\title{
Synthesis of chain-like $\mathrm{MoS}_{2}$ nanoparticles in $\mathrm{W} / \mathrm{O}$ reverse microemulsion and application in photocatalysis
}

\author{
LIU MeiYing*, LI XiaoQian, XU ZhiLing, LI BoNa, CHEN LinLin \& SHAN NanNan \\ Institute of Chemistry for Functionalized Materials, Faculty of Chemistry and Chemical Engineering, Liaoning Normal University, Dalian 116029, China
}

Received March 31, 2012; accepted May 30, 2012; published online June 29, 2012

Chain-like $\mathrm{MoS}_{2}$ assemblies consisting of hexagonal $\mathrm{MoS}_{2}$ nanoparticles (20-60 nm) have been successfully synthesized in a Triton X-100/cyclohexane/hexanol/water W/O reverse microemulsion in the presence of $\left(\mathrm{NH}_{4}\right)_{2} \mathrm{MoS}_{4}$ as the molybdenum source and $\mathrm{NH}_{2} \mathrm{OH} \cdot \mathrm{HCl}$ as the reducing agent. The products were characterized by X-ray powder diffraction (XRD), transmission electron microscopy (TEM) and UV-vis diffuse reflectance absorption spectra. The influence of synthetic parameters such as acidity, water/oil ratio $\left(\omega_{0}\right)$, aging time and annealing temperature on the formation of $\mathrm{MoS}_{2}$ assemblies was investigated. TEM analysis showed that these synthetic factors played important roles in controlling the size of $\mathrm{MoS}_{2}$ nanoparticles and the length of the chain-like $\mathrm{MoS}_{2}$ assemblies. XRD analysis indicated that the well-crystallized $\mathrm{MoS}_{2}$ nanoparticles could be obtained by annealing the precursors at $700^{\circ} \mathrm{C}$ for $2 \mathrm{~h}$ under a flow of $\mathrm{N}_{2}$ atmosphere. In addition, the as-prepared chain-like $\mathrm{MoS}_{2}$ nanoparticles exhibited excellent photocatalytic $\mathrm{H}_{2}$ activity in $\mathrm{Ru}(\mathrm{bpy})_{3}^{2+}-\mathrm{MoS}_{2}-\mathrm{H}_{2} \mathrm{~A}$ three-component molecular systems under visible light irradiation.

chain-like, $\mathrm{MoS}_{2}$, reverse microemulsion, photocatalytic, $\mathrm{H}_{2}$

Citation: Liu M Y, Li X Q, Xu Z L, et al. Synthesis of chain-like $\mathrm{MoS}_{2}$ nanoparticles in W/O reverse microemulsion and application in photocatalysis. Chin Sci Bull, 2012, 57: 3862-3866, doi: 10.1007/s11434-012-5339-0

The family of layered transition metal chalcogenides, such as $\mathrm{MoS}_{2}, \mathrm{WS}_{2}$, has aroused considerable interest during the past decade because of their unique properties and potential applications in hydrodesulfurization, $\mathrm{Mg}^{2+}$ and $\mathrm{Li}^{+}$batteries, and solar photocells [1-4]. Increasing attention is now being focused on their potential applications as promising candidates for $\mathrm{Pt}$, a co-catalyst and as well as a catalyst in photocatalytic $\mathrm{H}_{2}$ production [5,6]. As it is well known, $\mathrm{MoS}_{2}$ is an indirect, narrow band gap semiconductor $\left(E_{\mathrm{g}}=1.0-1.2 \mathrm{eV}\right.$, covering the range of solar spectrum energy) with high stability against photocorrosion in solution [7]. The band gap of $\mathrm{MoS}_{2}$ depends on its crystallinity, size and shape due to the quantum confinement effect. Therefore, considerable effort has been made to the synthesis of $\mathrm{MoS}_{2}$ nanomaterials with desired size and morphology. This material can be prepared under hydrothermal, solvothermal, sonolysis, inverse micelle, and $\gamma$-irradiation conditions [8-12]. Among

*Corresponding author (email: myliu312@yahoo.com) the methods, the inverse micelle synthesis has been proven to be a convenient, effective and promising method to regulate the size and morphology of $\mathrm{MoS}_{2}$. In this approach, particles are grown inside inverse micelle cages dispersed in non-aqueous solvents. The particle size and morphology of $\mathrm{MoS}_{2}$ crystals can be tailored through controlling the micelle size, which can be easily achieved by changing the emulsifier/water ratio. For example, Wilcoxon et al. [13,14] synthesized the nanosized $\mathrm{MoS}_{2}$ crystals as small as 2.5 and $4 \mathrm{~nm}$ in EHAB/hexanol/octane and TDAB/hexanol/octane micelle solutions. Chikan et al. [15] obtained $\mathrm{MoS}_{2}$ nanocrystals with the size of $3.5,4.5$ and $8 \mathrm{~nm}$ in DDAB/hexanol/ octane and TDAI/hexanol/octane ternary micelles, respectively. Osseo-Asare and co-workers [11] got $\mathrm{MoS}_{2}$ nanoparticles ranging 10-80 $\mathrm{nm}$ in NP-5/cyclohexane/water microemulsion system. Xie and co-workers [16] fabricated necklace-shaped assembly of fullerene-like $\mathrm{MoS}_{2}$ nanospheres through a micelle-assisted route. Chain-like morphology is a novel nanostructure, which is attributed to 1D 
oriented assembly of nanoparticles. However, chain-like $\mathrm{MoS}_{2}$ assemblies have received much less attention though they are likely to play a critical role in the improvement of the efficiencies of various devices based on single particles and provide a direct bridge between nanometer-scale objects and the macroscale world. Here, we report a W/O reverse microemulsion approach to synthesize $\mathrm{MoS}_{2}$ nanoparticles in the size range $20-60 \mathrm{~nm}$ in a Triton X-100/cyclohexane/hexanol/water quaternary micelle solutions in the presence of $\left(\mathrm{NH}_{4}\right)_{2} \mathrm{MoS}_{4}$ as the molybdenum source and $\mathrm{NH}_{2} \mathrm{OH} \cdot \mathrm{HCl}$ as the reducing agent. Interestingly, the asobtained $\mathrm{MoS}_{2}$ nanoparticles were assembled to a chain-like structure with several $\mu \mathrm{m}$ in length. Moreover, the photocatalytic $\mathrm{H}_{2}$ activity of chain-like $\mathrm{MoS}_{2}$ nanoparticles was evaluated in three-component homogeneous molecular systems containing $\mathrm{MoS}_{2}$ nanoparticles as a catalyst, $\mathrm{Ru}(\mathrm{bpy})_{3}^{2+}$ as a photosensitizer (PS) and ascorbic acid $\left(\mathrm{H}_{2} \mathrm{~A}\right)$ as a sacrificial reagent under visible light $(\lambda>420 \mathrm{~nm})$ illumination.

\section{Experimental}

All chemicals used in this work are of analytical-grade reagents and were used without further purification. A nonionic W/O reverse micelle system, Triton X-100/hexanol/cyclohexane/water, was employed to synthesize the chain-like $\mathrm{MoS}_{2}$ assemblies. The procedure consists of four steps as follows: (1) the fabrication of the needle-like $\left(\mathrm{NH}_{4}\right)_{2} \mathrm{MoS}_{4}$ precursor according to the literature [17]; (2) two identical solutions were prepared by mixing Triton X-100 with hexanol at a fixed weight ratio of $4: 3$. The mixture was then dissolved in cyclohexane with a weight ratio of $6: 4$, and stirred until a clear solution resulted; (3) $3.2 \mathrm{~mL}\left(\mathrm{NH}_{4}\right)_{2}$ $\mathrm{MoS}_{4}$ aqueous solution $(0.1 \mathrm{~mol} / \mathrm{L})$ or $3.2 \mathrm{~mL} \mathrm{NH} \mathrm{NH}_{2} \mathrm{OHCl}$ $(0.3 \mathrm{~mol} / \mathrm{L})$ with $\mathrm{HCl}(0.8 \mathrm{~mol} / \mathrm{L})$ aqueous solution was added into the oil phase in which the content of aqueous solution was controlled at $\omega_{0}=10\left(\omega_{0}\right.$ is defined as the molar ratio of water to surfactant). The microemulsion solution was stirred until it became transparent and stable; (4) the two optically transparent inverse micelle solutions were slowly combined and stirred for additional $2 \mathrm{~h}$. After the combined inverse micelle system was placed and aged for 3 days, the as-obtained $\mathrm{MoS}_{2}$ samples were annealed in a tube furnace in a stream of $\mathrm{N}_{2}$ at $700^{\circ} \mathrm{C}$ for $2 \mathrm{~h}$.

The crystal structure and phase purity of the samples were determined by X-ray diffraction (XRD) on a Bruker D8 Advance diffractometer with monochromatized $\mathrm{Cu} \mathrm{K \alpha}$ radiation $(\lambda=1.54178 \AA)$. The morphology and size of the products were measured by a JEOL JEM-1200 transmission electron microscopy (TEM) at $100 \mathrm{kV}$. UV-vis absorption spectra were recorded in the wavelength range of 250-800 $\mathrm{nm}$ on a Perkin-Elmer Lambda $3 \mathrm{UV}$-vis spectrophotometer after the sample being dispersed in ethanol. The photocatalytic reaction was carried out in a closed gas circulation and evacuation system under a $300 \mathrm{~W}$ Xenon lamp equipped with a cut-off filter $(\lambda>420 \mathrm{~nm})$. The freshly prepared $\mathrm{MoS}_{2}$ $(0.02 \mathrm{~g})$ nanoparticles were well dispersed by magnetic stirring into $200 \mathrm{~mL}$ of $2: 1(\mathrm{v}: \mathrm{v})$ acetonitrile/methanol solution containing $20 \mu \mathrm{mol} \mathrm{Ru(bpy)})_{3} \mathrm{Cl}_{2}$ and $0.01 \mathrm{~mol} \mathrm{H}_{2} \mathrm{~A}$. The evolved $\mathrm{H}_{2}$ was analyzed online by gas chromatography with a thermal conductivity detector.

\section{Results and discussion}

Figure 1 shows the XRD patterns of $\mathrm{MoS}_{2}$ chains synthesized (a) without and (b) with adding $0.8 \mathrm{~mol} / \mathrm{L} \mathrm{HCl}$ solution, and (c) after annealing of (a) under $\mathrm{N}_{2}$ flow at $700^{\circ} \mathrm{C}$ for $2 \mathrm{~h}$, respectively. All diffraction peaks can be readily identified as a pure phase of hexagonal $2 \mathrm{H}$ (two-layer hexagonal) $\mathrm{MoS}_{2}$ with calculated lattice constants of $a=3.161 \AA$, $c=12.299 \AA$, which is consistent with the data of JCPDS card 37-1492 $\left(\mathrm{P}_{2} / \mathrm{mmc}^{-\mathrm{D}_{6 h}^{4}}\right)$. There is only a weak peak at $2 \theta=14.4^{\circ}$ corresponding to diffraction of (002) plane of crystalline $\mathrm{MoS}_{2}$, revealing the poor crystallization of $\mathrm{MoS}_{2}$ chains (Figure 1(a)). As to the sample obtained by the acidmediated microemulsion, in addition to the weak (002) peak, diffractions from (100) and (110) planes appeared at the corresponding position as shown in Figure 1(b). The broad envelope peak of (100) diffraction as well as weak (002) peak are also indicative of the disordered stacking of $\mathrm{MoS}_{2}$ chains [18]. It has been reported that the crystallinity of $\mathrm{MoS}_{2}$ could be improved by annealing at a higher temperature [2]. Therefore, the $\mathrm{MoS}_{2}$ chain obtained in this study was annealed in $\mathrm{N}_{2}$ at $700^{\circ} \mathrm{C}$ for $2 \mathrm{~h}$ and its XRD pattern is presented in Figure 1(c). After annealing, all the diffraction peaks are much more intensive. The presence of the sharp peak of (002) indicates that the annealed $\mathrm{MoS}_{2}$ samples are highly crystalline with the well-stacked layered structure.

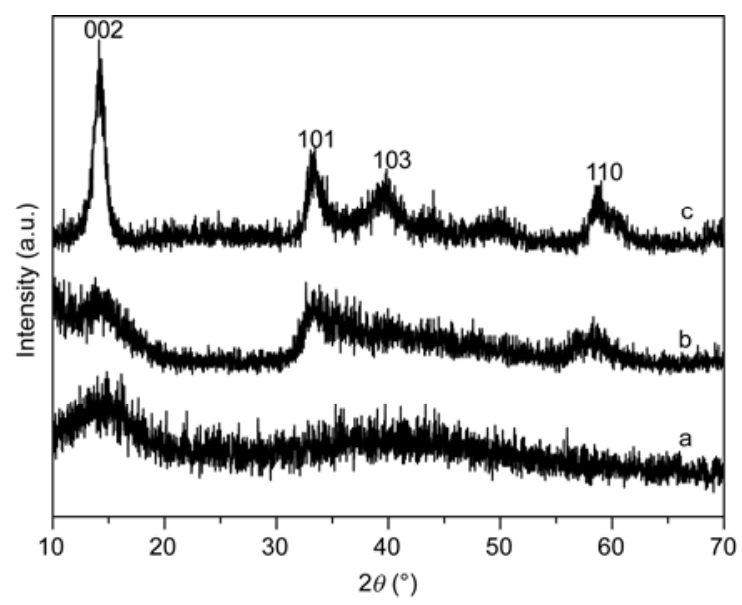

Figure 1 XRD patterns of $\mathrm{MoS}_{2}$ synthesized in W/O microemulsion $\left(\left[\left(\mathrm{NH}_{4}\right)_{2} \mathrm{MoS}_{4}\right]=0.1 \mathrm{~mol} / \mathrm{L},\left[\mathrm{NH}_{2} \mathrm{OH} \cdot \mathrm{HCl}\right]=0.3 \mathrm{~mol} / \mathrm{L}\right)$ aged for $3 \mathrm{~d}$ with $\omega_{0}=10$ (a) without (b) and with adding $0.8 \mathrm{~mol} / \mathrm{L} \mathrm{HCl}$ solution, and (c) after annealing of (a) in $\mathrm{N}_{2}$ at $700^{\circ} \mathrm{C}$ for $2 \mathrm{~h}$. 
The morphology and size of $\mathrm{MoS}_{2}$ chains were examined by TEM analysis. Figure 2 shows TEM images of $\mathrm{MoS}_{2}$ chains synthesized (a) without and (b) with adding $0.8 \mathrm{~mol} / \mathrm{L}$ $\mathrm{HCl}$ solution, and (c) after annealing of (a) under $\mathrm{N}_{2}$ flow at $700^{\circ} \mathrm{C}$ for $2 \mathrm{~h}$, respectively. As shown in Figure 2(a), the product is primarily composed of chain-like $\mathrm{MoS}_{2}$ with length of about several micrometers and diameter of $30 \mathrm{~nm}$. In addition, the chains assembled by $\mathrm{MoS}_{2}$ nanoparticles are obviously continuous and perfect. The chain-like morphology remains unchanged, while the $\mathrm{MoS}_{2}$ chains are much shaggier and the accumulations are observed as shown in Figure 2(b) for the products obtained via an acid-mediated microemulsion route. This can be explained as follows: after $\mathrm{HCl}$ solution was introduced into the system, the microemulsion was destroyed to some extent, leading to the aggregation of $\mathrm{MoS}_{2}$ nanoparticles. Figure 2(c) shows a typical TEM image of $\mathrm{MoS}_{2}$ samples after annealing in the flow of $\mathrm{N}_{2}$.

Many nanosheets besides the floccule structure were ob- served. They exhibit short-range layered arrays stacked in a fairly chaotic fashion, which is similar to the morphology reported by $\mathrm{Li}$ et al. [19]. This is attributed to the improvement of the crystallinity after annealing, which resulted in the extending of the weak layer along with (002) plane. In addition, the selected area electron diffraction (SAED) exhibit clear ring patterns (the inset of Figure 2(c)), revealing the polycrystalline nature of the as-synthesized $\mathrm{MoS}_{2}$ nanoparticles. The rings can be indexed respectively to the (100), (103), and (110) crystal diffractions of hexagonal $\mathrm{MoS}_{2}$. However, the diffraction ring patterns (the inset of Figure 2(a) and (b)) are obscure, showing the as-prepared $\mathrm{MoS}_{2}$ nanoparticles before annealing at high temperature are poorly crystallized. This coincides well with the results obtained from XRD patterns in Figure 1.

The effect of $\omega_{0}$ on the formation of $\mathrm{MoS}_{2}$ chains was also investigated. Figure 3 displays the TEM images of $\mathrm{MoS}_{2}$ chains synthesized inside the reverse micelle cages aged for $3 \mathrm{~d}$ with $\omega_{0}=6$ (a) and $\omega_{0}=15$ (b). When $\omega_{0}$ was 6 ,
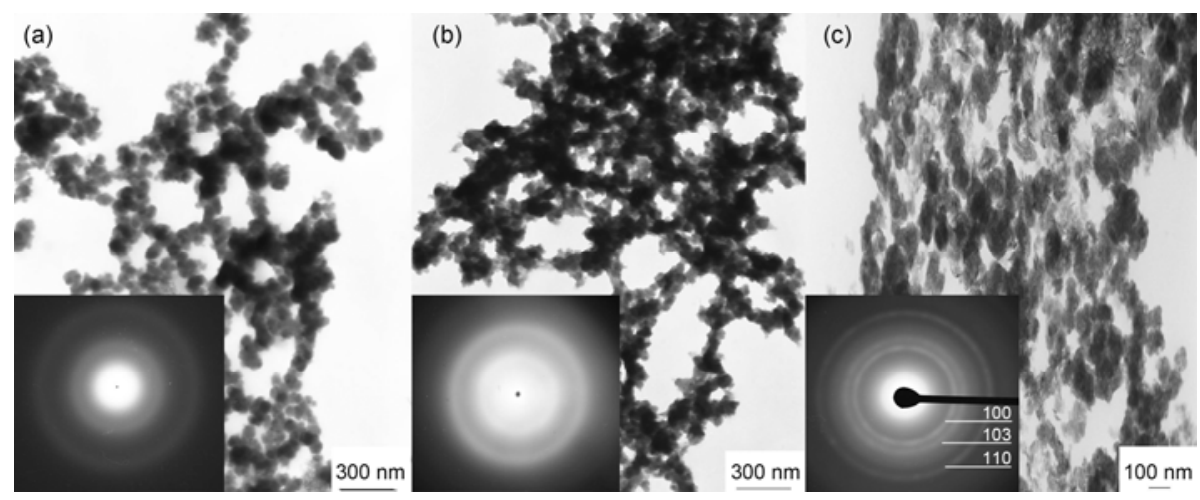

Figure 2 TEM images of $\mathrm{MoS}_{2}$ synthesized in W/O microemulsion $\left(\left[\left(\mathrm{NH}_{4}\right)_{2} \mathrm{MoS}_{4}\right]=0.1 \mathrm{~mol} / \mathrm{L},\left[\mathrm{NH}_{2} \mathrm{OH} \cdot \mathrm{HCl}\right]=0.3 \mathrm{~mol} / \mathrm{L}\right)$ aged for $3 \mathrm{~d}$ with $\omega_{0}=10(\mathrm{a})$ without (b) and with adding $0.8 \mathrm{~mol} / \mathrm{L} \mathrm{HCl}$ solution, and (c) after annealing of (a) in $\mathrm{N}_{2}$ at $700^{\circ} \mathrm{C}$ for $2 \mathrm{~h}$. The inset is the SAED pattern.
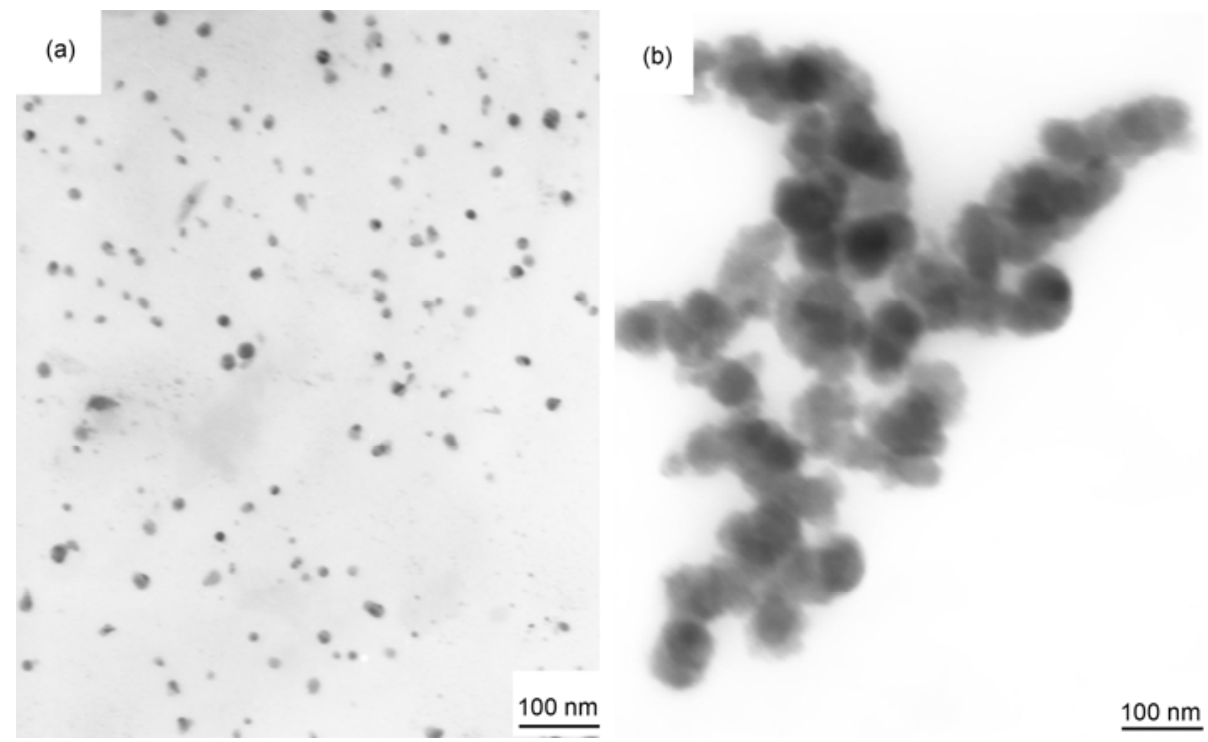

Figure 3 TEM images of $\mathrm{MoS}_{2}$ synthesized in W/O microemulsion $\left(\left[\left(\mathrm{NH}_{4}\right)_{2} \mathrm{MoS}_{4}\right]=0.1 \mathrm{~mol} / \mathrm{L},\left[\mathrm{NH}_{2} \mathrm{OH} \cdot \mathrm{HCl}\right]=0.3 \mathrm{~mol} / \mathrm{L}\right)$ aged for $3 \mathrm{~d}$ with $\omega_{0}=6($ a) and $\omega_{0}=15(b)$. 
the as-synthesized product is mainly composed of highly dispersed $\mathrm{MoS}_{2}$ particles with an average diameter of $20 \mathrm{~nm}$ (Figure 3(a)). When $\omega_{0}$ was 10 , the $\mathrm{MoS}_{2}$ chains assembled by nanoparticles of $\mathrm{MoS}_{2}$ with $30 \mathrm{~nm}$ in diameter are obtained (Figure 2(a)). An increase of $\omega_{0}$ to 15 leads to the formation of $\mathrm{MoS}_{2}$ chains with a diameter of $60 \mathrm{~nm}$ (Figure 3(b)). The broader size distribution of $\mathrm{MoS}_{2}$ nanoparticles with increasing $\omega_{0}$ can be explained as follows: at low $\omega_{0}$, water droplets in the reverse micelles are considered to be "bound" and insufficiently available to dissolve the surfactant head group and counterion [20]. With the water bound, the micelle interface is "rigid" and decreases the intermicellar exchange of reactants, thus lowering the growth rates of $\mathrm{MoS}_{2}$ nanoparticles. With increasing $\omega_{0}$, the microemulsion becomes more fluid, accelerating the growth of $\mathrm{MoS}_{2}$ chains.

Figure 4 gives the TEM images of $\mathrm{MoS}_{2}$ chains synthesized inside the reverse micelle cages with $\omega_{0}=10$. It can be found from the TEM images that the chain-like structure of $\mathrm{MoS}_{2}$ still remains, though the size is not the same as that of the sample aged for $3 \mathrm{~d}$ (Figure 2(a)). When the aging time was reduced to $1 \mathrm{~d}$ (Figure 4(a)), the diameter of the $\mathrm{MoS}_{2}$ chain is $20 \mathrm{~nm}$, and the length of the chain-like structure became shorter. After the aging time was extended to $5 \mathrm{~d}$ (Figure 4(b)), the mean diameter and the length of the $\mathrm{MoS}_{2}$ chain increased to $40 \mathrm{~nm}$ and several $\mu \mathrm{m}$, respectively. At a prolonged aging time from 1 to $15 \mathrm{~d}$, it can be found from TEM images in Figure 4(c) that the diameter of $\mathrm{MoS}_{2}$ chain was increased to $60 \mathrm{~nm}$. In addition, the aggregation of the chain-like structure was observed. Thus appropriate aging time is propitious to the growth of the $\mathrm{MoS}_{2}$ nanoparticles. As it is known, microemulsions are thermodynamically stable, which can be considered as intelligent nano-reactors with the function of self-organizability and copy. Due to the gravity effects, the extended aging time as well as the large molecular weight of $\mathrm{MoS}_{2}$ make the lipophilic group of the surfactant molecules gradually lost function that maintain the system stable, resulting in the particles irregularly aggregate and conglutinate one another [21].
The UV-vis diffuse reflectance absorption spectrum of $\mathrm{MoS}_{2}$ chains aged for $3 \mathrm{~d}$ with $\omega_{0}=10$ is displayed in Figure 5. The as-synthesized chain-like $\mathrm{MoS}_{2}$ nanoparticles exhibit strong absorption in UV region with a maximum at $276 \mathrm{~nm}$ and a weaker broad absorption in the visible region of 400 $\mathrm{nm}$, which is very similar to that of $\mathrm{MoS}_{2}$ nanoparticles reported by Zong et al. [6], Chikan et al. [15] and Zhang et al. [22]. The photocatalytic $\mathrm{H}_{2}$-production activity was determined by dispersing the freshly-prepared $\mathrm{MoS}_{2}$ nanoparticles in a $200 \mathrm{~mL}$ acetonitrile/methanol $(\mathrm{v}: \mathrm{v}, 2: 1)$ solution containing $\mathrm{Ru}(\mathrm{bpy})_{3}^{2+}$ and $\mathrm{H}_{2} \mathrm{~A}$ under visible light $(\lambda>420 \mathrm{~nm})$ irradiation, as shown in Figure 6. About $158 \mu \mathrm{mol}$ of $\mathrm{H}_{2}$ were evolved in a six hour photocatalytic reaction in the presence of $0.02 \mathrm{~g}(11.9 \mu \mathrm{mol})$ of $\mathrm{MoS}_{2}$, and $20 \mu \mathrm{mol}$ of $\mathrm{Ru}(\mathrm{bpy})_{3}^{2+}$. The turnover number of $\mathrm{H}_{2}$ evolution was calculated to be 27 and 16, based on $\mathrm{MoS}_{2}$ and $\mathrm{Ru}(\mathrm{bpy})_{3}^{2+}$, respectively. The $\mathrm{H}_{2}$-evoultion activity of the as-synthesized chainlike $\mathrm{MoS}_{2}$ nanoparticles in the $\mathrm{Ru}(\mathrm{bpy})_{3}^{2+}-\mathrm{MoS}_{2}-\mathrm{H}_{2} \mathrm{~A}$ homogeneous molecular system is much superior to that of the traditional $\mathrm{MoS}_{2} / \mathrm{Al}_{2} \mathrm{O}_{3}$ catalyst which generally exhibits excellent $\mathrm{H}_{2}$ activity in heterogeneous catalysis. This is attributable to the facile electron migration between the catalyst and the reactant due to the small particle size and good dispersibility of $\mathrm{MoS}_{2}$ nanoparticles in acetonitrile/methanol solution $[6,23]$.

\section{Conclusions}

In summary, chain-like $\mathrm{MoS}_{2}$ assemblies with a length up to several $\mu \mathrm{m}$, consisting of $\mathrm{MoS}_{2}$ nanoparticles with tunable diameter of 20-60 nm, have been successfully grown inside a Triton X-100/cyclohexane/hexanol/water nonionic W/O inverse micelle cages in the presence of $\left(\mathrm{NH}_{4}\right)_{2} \mathrm{MoS}_{4}$ as molybdenum source and $\mathrm{NH}_{2} \mathrm{OH} \cdot \mathrm{HCl}$ as reducing agent. The acidity, $\omega_{0}$ and the aging time play important roles in tailoring the morphology and size of $\mathrm{MoS}_{2}$ chain. The as-synthesized chain-like $\mathrm{MoS}_{2}$ nanoparticles has been demonstrated to function as an efficient photocatalyst for $\mathrm{H}_{2}$

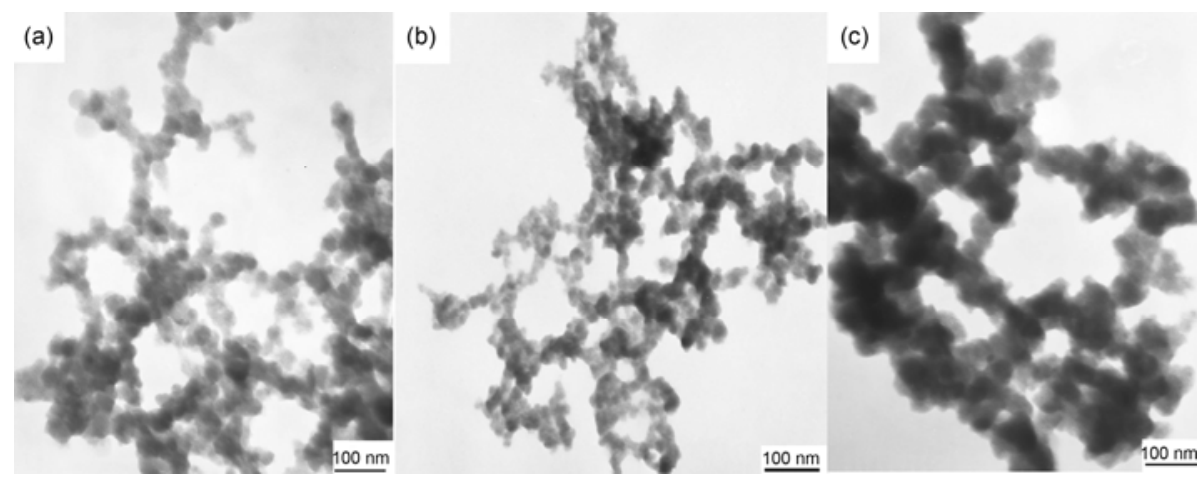

Figure 4 TEM images of $\mathrm{MoS}_{2}$ synthesized in W/O microemulsion $\left(\left[\left(\mathrm{NH}_{4}\right)_{2} \mathrm{MoS}_{4}\right]=0.1 \mathrm{~mol} / \mathrm{L},\left[\mathrm{NH}{ }_{2} \mathrm{OH} \cdot \mathrm{HCl}\right]=0.3 \mathrm{~mol} / \mathrm{L}\right)$ aged for $(\mathrm{a}) 1$, (b) 5 and $(\mathrm{c}) 15$ d with $\omega_{0}=10$. 


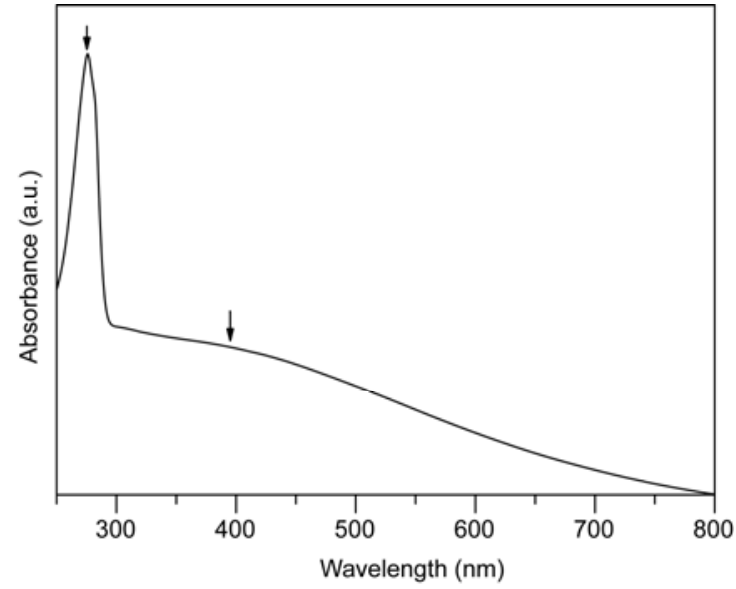

Figure 5 UV-vis diffuse reflectance absorption spectrum of $\mathrm{MoS}_{2}$ synthesized in W/O microemulsion $\left(\left[\left(\mathrm{NH}_{4}\right)_{2} \mathrm{MoS}_{4}\right]=0.1 \mathrm{~mol} / \mathrm{L},\left[\mathrm{NH}_{2} \mathrm{OH} \cdot \mathrm{HCl}\right]=\right.$ $0.3 \mathrm{~mol} / \mathrm{L})$ aged for $3 \mathrm{~d}$ with $\omega_{0}=10$.

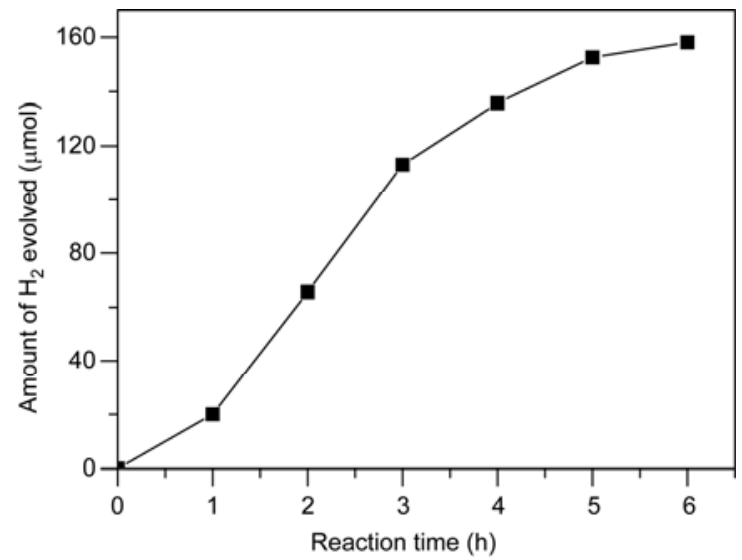

Figure 6 Photocatalytic $\mathrm{H}_{2}$ evolution from a 2:1 acetonitrile/methanol $(200 \mathrm{~mL})$ solution in $\mathrm{Ru}(\mathrm{bpy})_{3}^{2+}-\mathrm{MoS}_{2}-\mathrm{H}_{2} \mathrm{~A}$ system under visible light irradiation. $\mathrm{MoS}_{2}$ : $11.9 \mu \mathrm{mol}, \mathrm{Ru}(\mathrm{bpy})_{3}^{2+}: 20 \mu \mathrm{mol}, \mathrm{H}_{2} \mathrm{~A}: 0.01 \mathrm{~mol}$, light source: $300 \mathrm{~W}$ Xe lamp $(\lambda>420 \mathrm{~nm})$.

evolution in $\mathrm{Ru}(\mathrm{bpy})_{3}^{2+}-\mathrm{MoS}_{2}-\mathrm{H}_{2} \mathrm{~A}$ homogeneous molecular system under visible light irradiation.

This work was supported by the National Natural Science Foundation of China (20803033), the National Basic Research Program of China (2009CB220010), the Scientific Research Foundation for the Returned Overseas Chinese Scholars, State Education Ministry and the Scientific Research Fund of Liaoning Provincial Education Department (L2010225). We are also grateful to Ms Yi Ma for her help in the photocatalytic reaction test.

1 Farag H, Al-Megren H. Textural characterizations and catalytic properties of quasispherical nanosized molybdenum disulfide. J Col- loid Interface Sci, 2009, 332: 425-431

2 Li X L, Li Y D. MoS 2 nanostructures: Synthesis and electrochemical $\mathrm{Mg}^{2+}$ intercalation. J Phys Chem B, 2004, 108: 13893-13900

3 Wang Q, Li J H. Facilitated lithium storage in $\mathrm{MoS}_{2}$ overlayers supported on coaxial carbon nanotubes. J Phys Chem C, 2007, 111: 1675-1682

4 Yang T T, Feng X, Tang Q L, et al. A facile method to prepare $\mathrm{MoS}_{2}$ with nanolameller-like morphology. J Alloys Compd, 2011, 509: 236-238

5 Zong X, Yan $\mathrm{H} \mathrm{J}$, Wu G P, et al. Enhancement of photocatalytic $\mathrm{H}_{2}$ evolution on CdS by loading $\mathrm{MoS}_{2}$ as cocatalyst under visible light irradiation. J Am Chem Soc, 2008, 130: 7176-7177

6 Zong $\mathrm{X}, \mathrm{Na} \mathrm{Y}$, Wen $\mathrm{F}$ Y, et al. Visible light driven $\mathrm{H}_{2}$ production in molecular systems employing colloidal $\mathrm{MoS}_{2}$ nanoparticles as catalyst. Chem Commun, 2009, 4536-4538

7 Coehoorn R, Haas C, Dijkstra J, et al. Electronic structure of $\mathrm{MoSe}_{2}$, $\mathrm{MoS}_{2}$, and $\mathrm{WSe}_{2}$. I. Band-structure calculations and photoelectron spectroscopy. Phys Rev B, 1987, 35: 6195-6202

8 Pourabbas B, Jamshidi B. Preparation of $\mathrm{MoS}_{2}$ nanoparticles by a modified hydrothermal method and the photo-catalytic activity of $\mathrm{MoS}_{2} / \mathrm{TiO}_{2}$ hybrids in photo-oxidation of phenol. Chem Eng J, 2008, 138: 55-62

9 Zhan J H, Zhang Z D, Qian X F, et al. Solvothermal synthesis of nanocrystalline $\mathrm{MoS}_{2}$ from $\mathrm{MoO}_{3}$ and elemental sulfur. J Solid State Chem, 1998, 141: 270-273

10 Mdeleni M M, Hyeon T, Suslick K S. Sonochemical synthesis of nanostructured molybdenum sulfide. J Am Chem Soc, 1998, 120: 6189-6190

11 Boakye E, Radovic L R, Osseo-Asare K. Microemulsion-mediated synthesis of nanosized molybdenum sulfide particles. J Colloid Interface Sci, 1994, 163: 120-129

12 Chu G, Bian G, Fu Y, et al. Preparation and structural characterization of nano-sized amorphous powders of $\mathrm{MoS}_{2}$ by $\gamma$-irradiation method. Mater Lett, 2000, 43: 81-86

13 Wilcoxon J P, Newcomer P P, Samara G A. Synthesis and optical properties of $\mathrm{MoS}_{2}$ and isomorphous nanoclusters in the quantum confinement regime. J Appl Phys, 1997, 81: 7934-7944

14 Wilcoxon J P, Samara G A. Strong quantum-size effects in a layered semiconductor: $\mathrm{MoS}_{2}$ nanoclusters. Phys Rev B, 1995, 51: 7299_ 7302

15 Chikan V, Kelley D F. Size-dependent spectroscopy of $\mathrm{MoS}_{2}$ nanoclusters. J Phys Chem B, 2002, 106: 3794-3804

16 Xiong Y J, Xie Y, Li Z Q, et al. Micelle-assisted fabrication of necklace-shaped assembly of inorganic fullerene-like molybdenum disulfide nanospheres. Chem Phys Lett, 2003, 382: 180-185

17 Liu C G, Chai Y M, Zhao H J, et al. PRC Patent, CN1557697, 2004 02-13

18 Joensen P, Frindt R F, Morrison S R. Single-layer $\mathrm{MoS}_{2}$. Mater Res Bull, 1986, 21: 457-461

$19 \mathrm{Li}$ Q, Li M, Chen Z Q, et al. Simple solution route to uniform $\mathrm{MoS}_{2}$ particles with randomly stacked layers. Mater Res Bull, 2004, 39: 981-986

20 Pileni M P. Nanosized particles made in colloidal assemblies. Langmuir, 1997, 13: 3266-3276

21 Lopez-Quintela M A. Synthesis of nanomaterials in microemulsions: Formation mechanisms and growth control. Curr Opin Colloid Interface Sci, 2003, 8: 137-144

22 Zhang Z J, Zhang J, Xue Q J. Synthesis and characterization of a molybdenum disulfide nanocluster. J Phys Chem, 1994, 98: 1297312977

23 Kiwi J, Gratzel M. Hydrogen evolution from water induced by visible light mediated by redox catalysis. Nature, 1979, 281: 657-658

Open Access This article is distributed under the terms of the Creative Commons Attribution License which permits any use, distribution, and reproduction in any medium, provided the original author(s) and source are credited. 